\title{
Effect of Health Education Program Based on Health Belief Model on Prognosis of Urinary Tract Infection in Pregnant Women
}

\author{
Manar Fathy Heiba Ed Baker ${ }^{1}$, Entisar Abo -Elghite Elhossiny Elkazeh ${ }^{2}$ \\ ${ }^{1}$ Assistant Professor of Maternity, Obstetrics and Gynecological Nursing. Faculty of Nursing, \\ Port-Said city, Egypt, \\ ${ }^{2}$ Assistant professor of Community Health Nursing, Faculty of Nursing, Tanta University, \\ Egypt.
}

\begin{abstract}
:
Background: Urinary tract infection is a common cause of morbidity in pregnant women. The success of any educational intervention rests on the proper application of health behavior theories and models. Aim of the study was to investigate the effect of a health education program based on Health Belief Model (HBM) on the prognosis of Urinary Tract infection (UTI) in pregnant women. The study hypothesis was that women's knowledge and practices will be improved, and this will lead to improvements in UTI symptoms and urine culture.
\end{abstract} Subjects \& methods: Research design: an open label controlled quasi-experimental study with pre-post assessment was used in this study. Setting: the antenatal care (ANC) clinics in the primary health care centers affiliated to the Ministry of Health in urban areas of Port-Said city. Subjects: consisted of 90 pregnant women in first and second trimesters diagnosed with UTI were recruited consecutively in the study sample, each woman was randomly assigned to either the intervention or the control group as 45 women per group.Tools of data collection: include; structure interview schedule and a lab sheet. Results: showed that majority were living in urban areas, with no formal education. More women had a history of previous UTI (53.3\% versus $40.0 \%$ ) for studied and control women respectively. no statistically significant differences in their baseline (pre-intervention) scores of symptoms, knowledge of UTI, related health behavior practices, or Health Belief Model (HBM). At the post-intervention phase, the scores of symptoms severity and bothersome were statistically significantly lower among the study group with median scores zero. The knowledge and health behavior practices scores were statistically significantly higher among the study group with knowledge medians 81.00 and 31.00 respectively $(\mathrm{p}<0.001)$. The scores of HBM were statistically significantly higher among the study group $(\mathrm{p}<0.001)$. The pus cells and the urine culture in urine were less among the study group both in the post and 3-month follow up samples $(p<0.001)(p=0.03)$, respectively. Conclusion: the study concluded that the study intervention was protective against the risk of having a positive urine culture at 3-months follow-up. Recommendations: the study recommended that the program and its booklet should be implemented in ANC settings.

Key Words: Health Belief Model (HBM); Urinary Tract infection (UTI); Pregnant women. 


\section{Introduction}

Urinary Tract Infection (UTI), a distressing disorder for affected individuals, is one of the most prevalent infections, and is associated with high healthcare and social expenditure ${ }^{(1)}$. The UTI term covers a wide spectrum of clinical ailments ranging from simple bacteriuria with no symptoms to serious infections of the kidneys and urinary tract. Pregnant women are considered the most susceptible to UTI ${ }^{(2)}$, so that the pregnancy-related UTI is considered the main cause of obstetrical hospitalization, and is associated with untoward maternal and fetal outcomes; this has been shown even with asymptomatic UTI ${ }^{(3)}$. The high prevalence of UTI in women, specifically pregnant women, makes it an important public health problem ${ }^{(4)}$. It is estimated that $25 \%$ of women get a UTI annually, and 40-50\% may have symptomatic UTI at least once during lifetime. The prevalence is fourfold among women compared with men. The prevalence rate among pregnant women is $7.2-10.4 \%$, and $20-40 \%$ of them ultimately have symptomatic UTI if left untreated ${ }^{(5)}$. Moreover, it has been shown that $20 \%$ of the parturient women may have colonies of Group B streptococci in urine ${ }^{(6)}$.

The success of any educational intervention rests on the proper application of health behavior theories and models. Such models proved to be effective in the area of health promotion as they help clarifying risk factors and changing health behaviors ${ }^{(7)}$. The Health Belief Model $(\mathrm{HBM})$ is based on how individual beliefs and fear from health problems and assessment of the benefits and barriers facing preventive actions lead to the embracing healthy behaviors ${ }^{(8)}$. It involves six constructs: perceived threat or possibility of getting ill, perceived severity of outcomes, stimuli as cues to action, perceived barriers for adopting a behavior, perceived benefits of the new behavior, and self-efficacy to perform the new behavior ${ }^{(9,10)}$. Hence, the HBM is deemed vital to clarify the relation between health beliefs and behaviors and is thus the model most frequently used in designing preventive educational programs ${ }^{(11,12,13)}$.

Significance of the study: Given the high burden of UTI in pregnant women in terms of prevalence and potential serious outcomes, this study tackles it as an important obstetric as well as public health problem. Although research addressed the problem from different aspects including diagnosis and management, there is still a paucity of research on educational interventions based on the HBM model as 
a framework. This study could add to the evidence of the effectiveness of educational interventions in improving the knowledge and preventive practices as well as the outcomes of UTI among pregnant women.

Aim of the study: To investigate the effect of a health education program based on Health Belief Model (HBM) on the prognosis of Urinary Tract infection (UTI) in pregnant women. The study hypothesis was that women's knowledge and practices will be improved, and this will lead to improvements in UTI symptoms and urine culture.

\section{Subjects and Method}

Research design and setting: This openlabel controlled quasi-experimental study with pre-post assessment was carried out at the antenatal care (ANC) clinics in the primary health care centers affiliated to the Ministry of Health in urban areas of PortSaid city. These centers provide free ANC services to residents in all districts of PortSaid city.

Subjects: Any pregnant women attending the study settings for ANC was targeted in this study. The inclusion criteria were being pregnant in the first or second trimesters and diagnosed as having UTI by urine culture (more than 100.000 colony forming unit $[\mathrm{CFU}] / \mathrm{ml}$ of urine). Women with known history of chronic renal disease, diabetes mellitus, or needing hospitalization were excluded. The sample size was calculated to demonstrate an improvement in women's scores of knowledge or practices with a moderate effect size $($ Cohen $\mathrm{D}=0.6)$. The required sample size per group at $95 \%$ level of confidence and $80 \%$ power was calculated as 45 women per group, and accounting for a dropout rate of about $10 \%{ }^{(14-15)}$.

Pregnant women were recruited consecutively in the study sample according to the inclusion and exclusion criteria. Then, each woman was randomly assigned to either the intervention or the control group. This was done using a simple random sampling technique with a list of computer-generated random numbers.

\section{Data collection tools:}

Structure interview schedule was used to obtain the necessary data for the study. This structure interview schedule includes the following parts.

Part I: This was for woman' demographic data as age, residence, education, job, and family income. It also involved woman's obstetric history, and history of vaginal or urinary tract infection.

Part II: This consisted of the UTI Symptoms Assessment scale (UTISA) developed by Clayson et al. (2005) ${ }^{(16)}$ to measure the severity and bothersome 


\section{Tanta Scientific Nursing Journal}

feeling of seven UTI symptoms (frequency, urgency, burning, inability to completely empty bladder, lower abdomen discomfort, low back pain, blood in urine). Each symptom was assessed separately for severity and bothersome on a 4-point Likert scale (absent, mild, moderate, severe for the severity subscale, and not-atall, a-little, moderately, a-lot for the bothersome scale). These were scored 0 to 3 . The average total scores of severity and bothersome were calculated by summingup the scores of the seven symptoms, and dividing it by seven. Thus, the total average score for each scale ranged from 0 to 3 , with a higher score indicating more severe and bothersome symptoms. This scale was applied to women at the pre- and post-intervention phases of the study.

Part III: This part was intended to measure woman's knowledge of UTI. It assessed knowledge about the definition of UTI, etiology and risk factor, symptoms and signs, complications, and management through 14 open-end questions, and 12 True/False questions. For scoring, the correct response for each question was scored 1 and the incorrect zero. The scores of all questions were summed-up and the total was converted into a percent score ranging from 0 to 100 so that a higher score indicates more satisfactory knowledge. Means and standard deviations and medians were computed at the pre- and post-intervention phases.

Part IV: This was concerned with woman's health behavior practices. It involved 30 items covering practices related to nutritional habits, personal cleanliness and perineal hygiene, suitability and care of underwear, urinary habits, and sexual hygiene and activity. Each item was to be checked on a fourpoint Likert scale ranging from "never" to "always," scored from zero to three respectively. For scoring, the scores of the items of each of the five categories and for the total scale were summed-up and the totals converted into percent scores ranging from 0 to 3 so that a higher score indicates more adequate practices. Means and standard deviations and medians were computed at the pre- and post-intervention phases.

Part V: This part assessed woman's sores of the Health Belief Model (HBM) related to UTI before and after the intervention. It had 30 statements that covered areas of perceived susceptibility such as "my living conditions are good, so I do not get urinary tract infection," severity such as "in case of a urinary tract infection, my fetus is at risk," barriers such as "it is not pleasant for me to urinate before and after coitus," and benefits such as "preventing Urinary Tract Infection prevents preterm 


\section{Tanta Scientific Nursing Journal}

delivery," self-efficacy such as "I know how to prevent urinary tract infections," and cues to action asking about sources of support. Each statement of the first five categories was to be checked on a 3-point Likert scale "disagree/uncertain/agree." For scoring, each item was scored from 1 to 3 respectively, with reverse scoring for negative items. Then, the scores of the items of each of category and for the total scale were summed-up and the totals converted into percent scores ranging from 1 to 3, with a higher score indicating better health belief. Means and standard deviations and medians were computed at the pre- and post-intervention phases.

The laboratory sheet tool was used to record the results of the lab analyses done for the woman. These were urine analysis for pus cells and urine culture. The tests were performed at the first visit before the intervention and at the end of treatment. The sheet was also used to record woman's compliance with the prescribed antibiotics course.

\section{Method}

Administrative

and

ethical

considerations: Official permission to conduct the study were obtained from concerned authorities. The study was implemented according to Helsinki Declaration for research ethics. An informed consent was obtained from each participant after full explanation of the study aim and maneuvers and of all participant rights. Data were treated in total confidentiality. The study maneuvers could not entail any harm on participants. All women were informed about their lab results, and proper management was offered equally to both groups. At the end of the program, the control group women were given the educational booklet and were encouraged to express any related inquiries.

\section{Content validity:}

Data collection tools were reviewed by five expertise in the maternity, obstetric, gynecologic nursing, and urology specialists to ensure applicability, comprehensiveness, understanding, and ease of implementation of the tools.

Reliability was done by cronbach's alpha coefficient test which revealed that each item of the utilized tools consisted relatively homogenous items. The internal consistency of knowledge was 0.89 ; the total HBM construct was 0.92 , and health behavior regarding UTIs was 0.75 .

Pilot study: A pilot study was carried out on 10 women to assess the suitability of the tools and feasibility of the study. It also helped in estimating the time needed for completion of the interviews and for getting the results of the lab investigations. The tools were finalized according to the 
pilot results, and these 10 women were not included in the main study sample.

Study maneuver: The study was carried out through assessment, planning, implementation, and evaluation phases.

Assessment phase: Upon securing official permissions, the researchers started recruitment of women in the intervention (to be administered the educational program) and control (to receive the routine care) groups. The women who gave their verbal consent to participate were interviewed individually using the interview questionnaire form. The interview for each woman took 20-25 minutes. Then, a clean catch mid-stream urine specimen according to the laboratory instructions (Higgins, 2013; Pernille et al., 2019) ${ }^{(17,18)}$ was taken from each woman, sent for lab analyses, and the results obtained were recorded on her lab sheet. The data obtained for symptoms, knowledge, practices, and HBM, as well as the lab results were considered as baseline or pre-test for final comparison. Women from both groups were then referred to physicians for treatment prescription.

Implementation phase: The educational program was applied by the researchers for the intervention group in five sessions 4560-minute each, over two weeks, and the study sample divided into eight groups which each group ranged from 5-6 women.
The first session was introductory. The second session addressed the HBM constructs of susceptibility and perceived severity, focusing on the high prevalence of UTI in pregnancy, and the associated complications. The third session was based on the HBM constructs of perceived benefits and barriers, where women were motivated to discuss the various barriers and how to overcome them to get the benefits of prevention of UTI and its complications. The fourth session addressed the self-efficacy construct of the HBM regarding the prevention and management of UTI, as well as the cues for action. The last session was for revision.

Adult learning methods were applied during implementation of the educational program, with more active participation from attendants, and more time for discussions. Various teaching methods were used including PowerPoint and video presentation, role playing, and demonstration with models. At the end of the program, an illustrated educational booklet was provided to participants for future reference and as a cue for action.

Evaluation phase: Women in both groups were interviewed again two weeks from recruitment. This constituted the postintervention test for the intervention group and a second test for the control group to be compared with the baseline scores of 
symptoms, knowledge, practice, and HBM.

A second clean catch mid-stream urine specimen following laboratory instructions was taken from each woman after completion of the prescribed antibiotics course and sent to the laboratory for analyses. This urine sampling and analysis was repeated after 3 months for follow-up. The results were recorded on the lab sheet.

Statistical analysis: Data entry and statistical analysis were carried out on SPSS 20.0 statistical software package. Data were presented using descriptive statistics in the form of frequencies and percentages for qualitative variables, and means and standard deviations and medians for quantitative variables. Cronbach alpha coefficient was calculated to assess the reliability of the scales used. Quantitative continuous data were compared using Student t-test or the nonparametric Mann-Whitney test as appropriate. Ccategorical variables were compared using chi-square test. Whenever the expected values in one or more of the cells in a $2 \times 2$ tables was less than 5, Fisher exact test was used instead. In order to identify the independent predictors of the scores of knowledge, practices, HBM, and symptoms, multiple linear regression analysis was used. To identify the independent predictors of the risk of having a positive second urine sample culture, multiple logistic regression analysis was used. Statistical significance was considered at $\mathrm{p}$-value $<0.05$.

\section{Results :}

Table (1): -The socio-demographic characteristics of the women in the two groups were similar with no significant differences between them. They had equal median age of 26 years, and the majority were living in urban areas, with no formal education, housewives, and having enough income.

Table (2): - Demonstrates similar obstetric history of the women in the study and control groups, with around two thirds of them being multigravidas and having living children, and one-third nulliparous. Less than a half (48.9\% and $42.2 \%)$ of the study women and control group reported having previously used contraception respectively, but only a few were using pregnancy spacing, $13.3 \%$ and $15.6 \%$ respectively. Slightly less than two-thirds were in the second trimester of the current pregnancy. More women in the study group had a history of previous UTI $(53.3 \%)$ in comparison with those in the control group $(40.0 \%)$ but the difference was not statistically significant $(\mathrm{p}=0.20)$.

As illustrates in Table (3), no statistically significant differences were noticed between the women in the study and control groups in their baseline (pre- 


\section{Tanta Scientific Nursing Journal}

intervention) scores of symptoms, knowledge of UTI, related health behavior practices, or Health Belief Model (HBM). The only exception was in the practice related to urinary habits. The median score (1.67) was statistically significantly higher among the women in the control group compared with 1.33 in the study group $(\mathrm{p}=0.01)$.

Table (4): - At the post-intervention phase, the scores of symptoms severity and bothersome were statistically significantly lower among the women in the study group in comparison with the control group, with median scores zero indicating that at least a half of them were symptom-free. Moreover, the knowledge and health behavior practices scores were statistically significantly higher among the women in the study group compared with the control group, with knowledge medians 81.00 and 31.00 respectively $(\mathrm{p}<0.001)$. Similarly, the scores of HBM were statistically significantly higher among the women in the study group in comparison with the control group $(\mathrm{p}<0.001)$.

Table (5): - Shows post-intervention statistically significant improvements in symptom severity and bothersome in both groups $(p<0.001)$. However, the mean score decrease was higher among the women in the study group, around twofold decrease in comparison with the control group. As regards to the knowledge and practice scores, they significantly improved only in the study group $(\mathrm{p}<0.001)$. The HBM scores improved in both groups, but the mean score increase was 0.9 compared with 0.1 in the control group.

Table (6): - Shows a higher compliance to treatment among the women in the study group $(88.9 \%)$ compared with $60.0 \%$ of those in the control group ( $\mathrm{p}=0.002)$. All women in the study group felt improved compared with $71.1 \%$ of those in the control group $(\mathrm{p}<0.001)$. The pus cells in urine were also less among the study group women both in the post and 3-months follow up women $(p<0.001)$. As for the urine culture at the post-intervention phase, it was $100 \%$ free among the women in the study group compared with $86.7 \%$ in the control group $(p=0.03)$. It was also significantly better among them at the 3months follow up phase.

In multiple linear regression analysis Table (7), the time and the study intervention were statistically significant independent positive predictors of the scores of knowledge, HBM, and health practices. Additionally, time was a positive predictor of the symptoms' severity and bothersome scores. Moreover, the knowledge score was a positive predictor of the HBM, practices, and symptoms 
scores. Lastly, urban residence and education were positive predictors of the knowledge score.

As displayed in (Table 8), the study intervention was protective against the risk of having a positive urine culture at 3month follow-up. The OR was 0.24 indicating that this risk is decreased to less than one-fourth, or reciprocally, the risk of positive culture is fourfold among those not having the educational program. Moreover, the HBM score is also protective with OR 0.14

Table (1): - Socio-demographic characteristics of women in the study and control groups

\begin{tabular}{|c|c|c|c|c|c|c|}
\hline \multirow{3}{*}{$\begin{array}{l}\text { Socio-demographic } \\
\text { characteristics }\end{array}$} & \multicolumn{4}{|c|}{ Group } & \multirow{3}{*}{$\mathrm{X}^{2}$ test } & \multirow{3}{*}{ p-value } \\
\hline & \multicolumn{2}{|c|}{ Study $(n=45)$} & \multicolumn{2}{|c|}{ Control $(n=45)$} & & \\
\hline & No. & $\%$ & No. & $\%$ & & \\
\hline \multicolumn{7}{|l|}{ Age: } \\
\hline$<25$ & 19 & 42.2 & 20 & 44.4 & & \\
\hline $25+$ & 26 & 57.8 & 25 & 55.6 & & \\
\hline Range & \multirow{3}{*}{\multicolumn{2}{|c|}{$\begin{array}{c}18-38 \\
26.2 \pm 4.9 \\
26.0\end{array}$}} & \multirow{3}{*}{\multicolumn{2}{|c|}{$\begin{array}{c}19-38 \\
26.4 \pm 5.0 \\
26.0\end{array}$}} & & \\
\hline Mean \pm SD & & & & & $\mathrm{t}=0.03$ & 0.87 \\
\hline Median & & & & & & \\
\hline \multicolumn{7}{|l|}{ Residence: } \\
\hline Rural & 14 & 45.2 & 17 & 37.8 & & \\
\hline Urban & 31 & 68.9 & 28 & 62.2 & 0.44 & 0.51 \\
\hline \multicolumn{7}{|l|}{ Formal education: } \\
\hline No & 34 & 75.6 & 35 & 77.8 & & \\
\hline Yes & 11 & 24.4 & 10 & 22.2 & 0.06 & 0.80 \\
\hline \multicolumn{7}{|l|}{ Job: } \\
\hline Housewife & 32 & 71.1 & 39 & 86.7 & & \\
\hline Working & 13 & 28.9 & 6 & 13.3 & 3.27 & 0.07 \\
\hline \multicolumn{7}{|l|}{ Family income: } \\
\hline Insufficient & 17 & 37.8 & 19 & 42.2 & & \\
\hline Enough & 28 & 62.2 & 26 & 57.8 & 0.19 & 0.67 \\
\hline
\end{tabular}


Table (2): - Obstetric history of women in the study and control groups

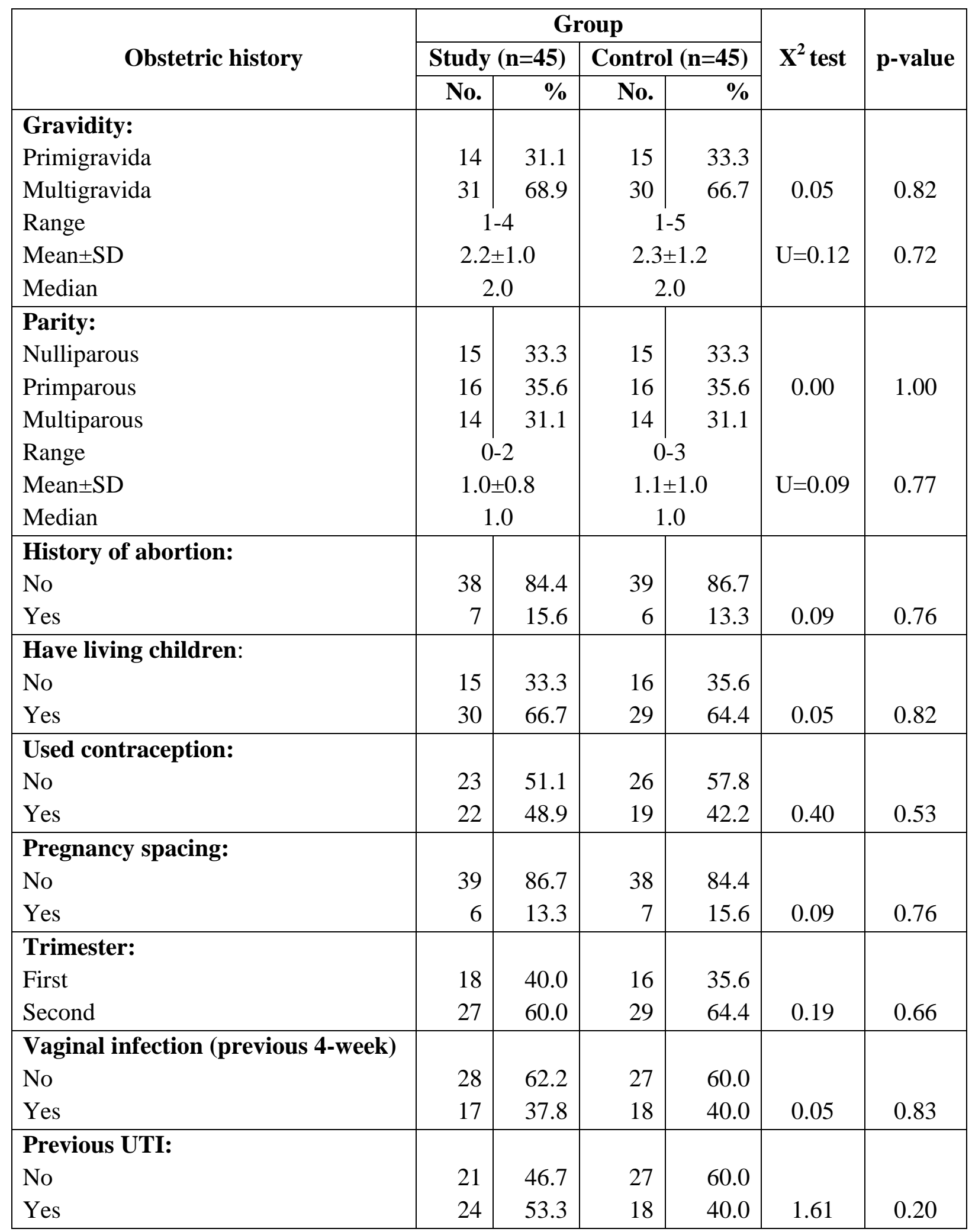


Table (3): Pre-intervention scores of symptoms, knowledge, practices, and health belief model (HBM) among women in the study and control groups

\begin{tabular}{|c|c|c|c|c|c|c|}
\hline \multirow{3}{*}{ Scores } & \multicolumn{4}{|c|}{ Group } & \multirow{3}{*}{$\begin{array}{c}\text { Mann } \\
\text { Whitney } \\
\text { Test }\end{array}$} & \multirow{3}{*}{ p-value } \\
\hline & \multicolumn{2}{|c|}{ Study $(n=45)$} & \multicolumn{2}{|c|}{ Control $(n=45)$} & & \\
\hline & Mean \pm SD & Median & Mean \pm SD & Median & & \\
\hline Symptoms: & & & & & & \\
\hline Severity $(\max =3)$ & $1.3 \pm 0.7$ & 1.29 & $1.1 \pm 0.6$ & 1.00 & 1.62 & 0.20 \\
\hline Bothersome ( $\max =3$ ) & $1.2 \pm 0.8$ & 1.29 & $1.1 \pm 0.6$ & 1.00 & 0.61 & 0.43 \\
\hline Overall $(\max =3)$ & $2.1 \pm 0.8$ & 2.00 & $2.0 \pm 0.7$ & 2.00 & 0.20 & 0.65 \\
\hline Knowledge $(\max =100)$ & & & & & & \\
\hline Knowledge & $31.5 \pm 19.6$ & 23.80 & $36.9 \pm 22.2$ & 28.60 & 0.97 & 0.33 \\
\hline Practices $(\max =3)$ : & & & & & & \\
\hline Nutrition & $1.2 \pm 0.5$ & 1.00 & $1.3 \pm 0.5$ & 1.20 & 2.34 & 0.13 \\
\hline Personal hygiene & $1.7 \pm 0.6$ & 1.71 & $1.7 \pm 0.5$ & 1.71 & 0.04 & 0.84 \\
\hline Clothing (underwear) & $1.8 \pm 0.9$ & 1.67 & $1.9 \pm 0.7$ & 1.67 & 0.40 & 0.53 \\
\hline Urinary habits & $1.4 \pm 0.8$ & 1.33 & $1.8 \pm 0.5$ & 1.67 & 6.10 & $0.01 *$ \\
\hline Sexual hygiene & $1.8 \pm 0.6$ & 1.71 & $1.6 \pm 0.6$ & 1.57 & 2.09 & 0.15 \\
\hline Total practice & $1.6 \pm 0.5$ & 2.00 & $1.7 \pm 0.5$ & 2.00 & 0.51 & 0.48 \\
\hline HBM $(\max =3)$ & & & & & & \\
\hline Perceived susceptibility & $1.7 \pm 0.6$ & 2.00 & $1.8 \pm 0.6$ & 2.00 & 0.01 & 0.89 \\
\hline Perceived severity & $1.8 \pm 0.6$ & 2.00 & $1.9 \pm 0.6$ & 2.00 & 0.25 & 0.62 \\
\hline Perceived barriers & $1.8 \pm 0.6$ & 2.00 & $1.9 \pm 0.7$ & 2.00 & 0.05 & 0.83 \\
\hline Perceived benefits & $2.2 \pm 0.6$ & 2.24 & $2.3 \pm 0.6$ & 2.60 & 0.41 & 0.52 \\
\hline Self-efficacy & $1.5 \pm 0.5$ & 1.43 & $1.5 \pm 0.6$ & 1.43 & 0.13 & 0.72 \\
\hline Cues to action & $0.4 \pm 0.3$ & 0.29 & $0.4 \pm 0.3$ & 0.29 & 0.02 & 0.90 \\
\hline Total HBM & $1.7 \pm 0.4$ & 1.80 & $1.8 \pm 0.4$ & 1.80 & 0.30 & 0.59 \\
\hline
\end{tabular}


Table (4): Post-intervention scores of symptoms, knowledge, practices, and health belief model (HBM) among women in the study and control groups

\begin{tabular}{|c|c|c|c|c|c|c|}
\hline \multirow{3}{*}{ Scores } & \multicolumn{4}{|c|}{ Group } & \multirow{3}{*}{$\begin{array}{c}\text { Mann } \\
\text { Whitney } \\
\text { Test }\end{array}$} & \multirow{3}{*}{ p-value } \\
\hline & \multicolumn{2}{|c|}{ Study $(n=45)$} & \multicolumn{2}{|c|}{ Control $(n=45)$} & & \\
\hline & Mean \pm SD & Median & Mean \pm SD & Mean \pm SD & & \\
\hline \multicolumn{7}{|l|}{ Symptoms: } \\
\hline Severity $(\max =3)$ & $0.1 \pm 0.2$ & 0.00 & $0.6 \pm 0.8$ & 0.14 & 5.77 & $0.02 *$ \\
\hline Bothersome $(\max =3)$ & $0.1 \pm 0.3$ & 0.00 & $0.5 \pm 0.8$ & 0.00 & 5.86 & $0.02 *$ \\
\hline Overall (max=3) & $0.5 \pm 0.7$ & 0.00 & $1.0 \pm 1.1$ & 1.00 & 4.42 & $0.04 *$ \\
\hline \multicolumn{7}{|l|}{ Knowledge $(\max =100)$} \\
\hline Knowledge & $79.8 \pm 12.7$ & 81.00 & $38.5 \pm 19.5$ & 31.00 & 55.04 & $<0.001 *$ \\
\hline \multicolumn{7}{|l|}{ Practices $(\max =3)$ : } \\
\hline Nutrition & $2.3 \pm 0.4$ & 2.20 & $1.3 \pm 0.5$ & 1.20 & 50.95 & $<0.001 *$ \\
\hline Personal hygiene & $2.5 \pm 0.4$ & 2.57 & $1.7 \pm 0.3$ & 1.71 & 49.54 & $<0.001 *$ \\
\hline Clothing (underwear) & $2.6 \pm 0.4$ & 2.67 & $1.9 \pm 0.6$ & 1.67 & 26.83 & $<0.001 *$ \\
\hline Urinary habits & $2.7 \pm 0.4$ & 2.67 & $1.8 \pm 0.5$ & 1.67 & 41.32 & $<0.001 *$ \\
\hline Sexual hygiene & $2.7 \pm 0.4$ & 2.86 & $1.6 \pm 0.5$ & 1.71 & 49.71 & $<0.001 *$ \\
\hline Total practice & $2.7 \pm 0.5$ & 3.00 & $1.7 \pm 0.5$ & 2.00 & 51.32 & $<0.001 *$ \\
\hline \multicolumn{7}{|l|}{ HBM $(\max =3)$} \\
\hline Perceived susceptibility & $2.6 \pm 0.6$ & 3.00 & $1.8 \pm 0.7$ & 2.00 & 26.41 & $<0.001 *$ \\
\hline Perceived severity & $2.8 \pm 0.4$ & 3.00 & $2.0 \pm 0.6$ & 2.00 & 45.19 & $<0.001 *$ \\
\hline Perceived barriers & $2.5 \pm 0.4$ & 2.57 & $1.9 \pm 0.7$ & 1.86 & 15.75 & $<0.001 *$ \\
\hline Perceived benefits & $2.9 \pm 0.4$ & 3.00 & $2.4 \pm 0.6$ & 2.60 & 26.44 & $<0.001 *$ \\
\hline Self-efficacy & $2.4 \pm 0.5$ & 2.29 & $1.6 \pm 0.6$ & 1.57 & 34.88 & $<0.001 *$ \\
\hline Cues to action & $0.9 \pm 0.2$ & 1.00 & $0.5 \pm 0.3$ & 0.43 & 42.06 & $<0.001 *$ \\
\hline Total HBM & $2.6 \pm 0.3$ & 2.66 & $1.8 \pm 0.4$ & 1.86 & 46.84 & $<0.001 *$ \\
\hline
\end{tabular}


Table (5): Post-pre-intervention differences in the scores of symptoms, knowledge, practices, and health belief model among women in the study and control groups

\begin{tabular}{|l|c|c|c|c|c|}
\hline $\begin{array}{c}\text { Scores of symptoms, } \\
\text { knowledge, practices, } \\
\text { and HBM }\end{array}$ & \multicolumn{3}{|c|}{ Post-pre difference } & Paired & p-value \\
\cline { 2 - 5 } t-test & Range & Mean \pm SD & Median & \\
\hline Study group: & $-2.29-(-2.0)$ & $-1.2 \pm 0.7$ & -1.14 & 11.80 & $<0.001^{*}$ \\
Symptom severity & $-2.1-0.0$ & $-1.1 \pm 0.7$ & -1.29 & 9.86 & $<0.001^{*}$ \\
Bothersome & $0.0-69.05$ & $48.3 \pm 15.5$ & 50.00 & 20.95 & $<0.001^{*}$ \\
Knowledge & $0.08-1.64$ & $1.0 \pm 0.4$ & 1.00 & 17.73 & $<0.001^{*}$ \\
Practice & $-0.2-1.9$ & $0.9 \pm 0.4$ & 0.74 & 13.56 & $<0.001^{*}$ \\
HBM & & & & & \\
Control group: & $-2.1-1.7$ & $-0.6 \pm 0.8$ & -0.57 & 4.99 & $<0.001^{*}$ \\
Symptom severity & $-2.1-2.0$ & $-0.5 \pm 0.8$ & -0.57 & 4.62 & $<0.001^{*}$ \\
Bothersome & $-9.5-11.9$ & $1.6 \pm 5.3$ & 2.38 & 2.01 & 0.051 \\
Knowledge & $-0.2-0.3$ & $0.0 \pm 0.1$ & 0.00 & 1.66 & 0.10 \\
Practice & $-0.1-0.7$ & $0.1 \pm 0.2$ & 0.00 & 2.28 & $0.03^{*}$ \\
HBM & \multicolumn{3}{|l}{} \\
\hline
\end{tabular}

Table (6): Compliance to treatment, improvement, and urine analyses results among women in the study and control groups

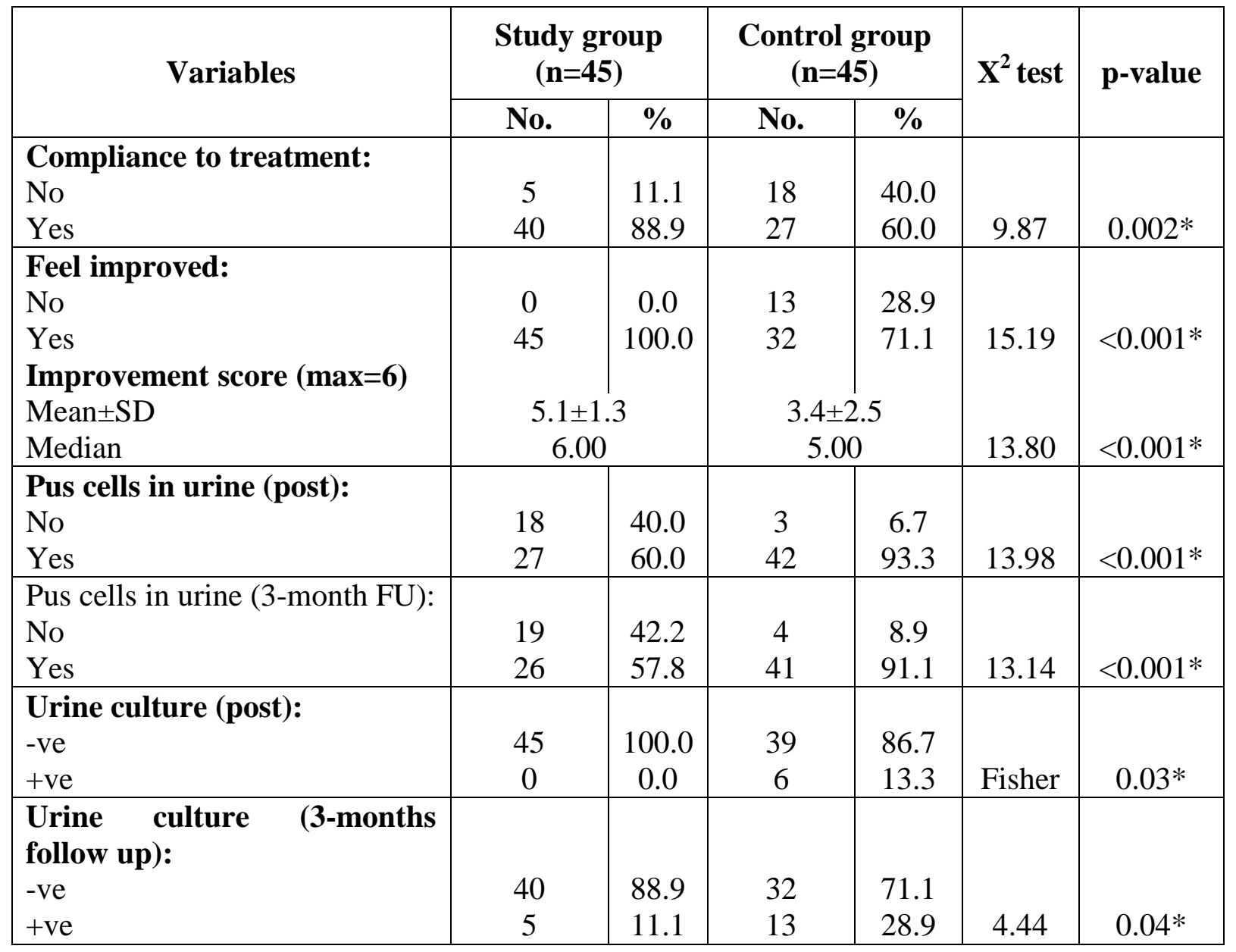


Table (7): Best fitting multiple linear regression model for women's knowledge, practice and Health Belief Model (HBM) scores

\begin{tabular}{|c|c|c|c|c|c|c|c|}
\hline & \multicolumn{2}{|c|}{$\begin{array}{l}\text { Unstandardized } \\
\text { Coefficients }\end{array}$} & \multirow{2}{*}{$\begin{array}{c}\text { Standardized } \\
\text { Coefficients }\end{array}$} & \multirow{2}{*}{ t-test } & \multirow{2}{*}{ p-value } & \multicolumn{2}{|c|}{$\begin{array}{l}95 \% \text { Confidence } \\
\text { Interval for B }\end{array}$} \\
\hline & B & Std. Error & & & & Lower & Upper \\
\hline \multicolumn{8}{|c|}{ Knowledge score } \\
\hline Constant & -13.29 & 3.57 & & -3.720 & $<0.001$ & -20.34 & -6.24 \\
\hline Time & 10.48 & 1.31 & 0.47 & 8.014 & $<0.001$ & 7.90 & 13.06 \\
\hline Intervention group & 7.23 & 1.31 & 0.32 & 5.520 & $<0.001$ & 4.65 & 9.82 \\
\hline Urban residence & 2.96 & 1.42 & 0.13 & 2.091 & 0.038 & 0.17 & 5.76 \\
\hline Education & 6.06 & 1.59 & 0.23 & 3.814 & $<0.001$ & 2.93 & 9.20 \\
\hline \multicolumn{8}{|c|}{$\begin{array}{l}\text { Model ANOVA: } \mathrm{F}=30.41, \mathrm{p}<0.001 \\
\text { luded: age, income, parity, past histor }\end{array}$} \\
\hline \multicolumn{8}{|c|}{ HBM score } \\
\hline Constant & 1.12 & 0.16 & & 6.786 & $<0.001$ & 0.79 & 1.44 \\
\hline Time & 0.22 & 0.07 & 0.22 & 3.319 & 0.001 & 0.09 & 0.36 \\
\hline Intervention group & 0.18 & 0.06 & 0.18 & 2.891 & 0.004 & 0.06 & 0.31 \\
\hline Knowledge score & 0.02 & 0.00 & 0.48 & 6.839 & $<0.001$ & 0.02 & 0.03 \\
\hline \multicolumn{8}{|c|}{ r-square $=0.44 \quad$ Model ANOVA: $\mathrm{F}=35.63, \mathrm{p}<0.001$} \\
\hline \multicolumn{8}{|c|}{ Practices score } \\
\hline Constant & .50 & .17 & & 2.973 & 0.003 & .17 & .82 \\
\hline Time & .31 & .09 & .24 & 3.629 & $<0.001$ & .14 & .48 \\
\hline Intervention group & .29 & .08 & .22 & 3.615 & $<0.001$ & .13 & .45 \\
\hline Knowledge score & .02 & .00 & .41 & 5.723 & $<0.001$ & .02 & .03 \\
\hline \multicolumn{8}{|c|}{ r-square $=0.45 \quad$ Model ANOVA: $\mathrm{F}=37.07, \mathrm{p}<0.001$} \\
\hline \multicolumn{8}{|c|}{ Symptom severity score } \\
\hline Constant & 2.15 & 0.15 & & 14.375 & $<0.001$ & 1.86 & 2.45 \\
\hline Time & -0.72 & 0.11 & -0.46 & -6.740 & $<0.001$ & -0.93 & -0.51 \\
\hline Knowledge score & -0.02 & 0.00 & -0.22 & -3.189 & 0.002 & -0.02 & -0.01 \\
\hline \multicolumn{8}{|c|}{$\begin{array}{l}\text { Model ANOVA: } \mathrm{F}=48.25, \mathrm{p}<0.001 \quad \text { Variables entered \& excluded: age, } \\
\text { nce, parity, past history of UTI, group, HBM, practice scores }\end{array}$} \\
\hline \multicolumn{8}{|c|}{ Bothersome score } \\
\hline Constant & 1.99 & 0.16 & & 12.458 & $<0.001$ & 1.67 & 2.30 \\
\hline Time & -0.66 & 0.11 & -0.42 & -5.826 & $<0.001$ & -0.88 & -0.44 \\
\hline Knowledge score & -0.01 & 0.01 & -0.20 & -2.752 & 0.007 & -0.02 & 0.00 \\
\hline $\begin{array}{l}\text { r-square }=0.28 \\
\text { education, income, }\end{array}$ & $\begin{array}{r}\text { Mode } \\
\text { ence, pa }\end{array}$ & $\begin{array}{l}\text { ANOVA: F } \\
\text { ty, past histo }\end{array}$ & $\begin{array}{l}=36.02, \mathrm{p}<0.00 \\
\text { ory of UTI, grou }\end{array}$ & 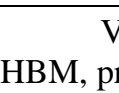 & $\begin{array}{l}\text { les en } \\
\text { e score }\end{array}$ & ed \& & led: age \\
\hline
\end{tabular}


Tanta Scientific Nursing Journal

Table (8): Best fitting multiple logistic regression model for women's risk of positive 3month FU urine culture

\begin{tabular}{|l|c|c|c|c|c|c|}
\hline & Wald & \multirow{2}{*}{ Df } & \multirow{2}{*}{ P } & \multirow{2}{*}{ OR } & \multicolumn{2}{|c|}{$\begin{array}{c}\text { 95.0\% CI } \\
\text { for OR }\end{array}$} \\
\cline { 4 - 7 } & & & & & Upper & Lower \\
\hline Constant & 5.59 & 1 & .018 & 49.38 & & \\
\hline $\begin{array}{l}\text { Intervention } \\
\text { group }\end{array}$ & 5.23 & 1 & .022 & 0.24 & 0.07 & 0.82 \\
\hline HBM score & 6.69 & 1 & .010 & 0.14 & 0.03 & 0.62 \\
\hline
\end{tabular}

Nagelkerke R Square: 0.201

Hosmer and Lemeshow Test: $\mathrm{p}=0.174$

Omnibus Tests of Model Coefficients: $\mathrm{p}<0.001$

Variables entered: group, age, residence, education, parity, history of UTI, scores of knowledge, HBM, practice 


\section{Discussion}

The current study hypothesized that women's knowledge and practices will be improved after implementing a health education program based on Health Belief Model (HBM), this will lead to improvements in UTI symptoms and urine culture. The findings demonstrated significant improvements in women's knowledge and health behavior practices, and this was associated with significant improvements in their UTI symptoms, as well as in their laboratory findings in comparison with control group women. Thus, the research hypothesis can be accepted.

The study and control group women in the present study had closely similar sociodemographic characteristics. They also had analogous obstetric and gynecological history. This similarity was essential for a fair comparison of the two groups given that the design is quasi-experimental and not truly randomized. Moreover, multivariate analysis was used to adjust for any confounding factors that might have an impact on the effect of the intervention on the various dependent study outcomes. Nonetheless, the limitations of the quasiexperimental design should be considered in the interpretation of the study findings as highlighted by Noya et al. (2020) ${ }^{(19)}$.
According to the present study findings, around a half of the women in the study and control groups reported a history of previous UTI. This is a relatively high prevalence rate that adds to the significance of the study given that the problem constitutes a high burden in this community. A similarly high prevalence of UTI was reported among Ethiopian pregnant women, with a high history of previous UTI among them (Gessese et al., 2017) (20). Similar findings were also reported among pregnant women attending ANC services in India (Kan et al.,2017) (21), as well as in Jordan (Clouse et al., 2019) (6). Moreover, pregnancy was identified as the main risk factor for UTI among women in Ghana (Donkor et al., 2019) ${ }^{(22)}$.

The present study results demonstrated that the women in the study and control groups were having low scores knowledge of UTI, as well as in their related health behavior practices. Moreover, their Health Belief Model (HBM) scores were low, indicating low perception of susceptibility to UTI, its severity, barriers and benefits of prevention and early management, as well as their self-efficacy. These low scores might be attributed to the characteristics of these women who are mostly young, illiterate, and not working. In congruence with this, a study in Bangladesh 
demonstrated that the prevalence and prognosis of UTI among pregnant women was significantly influenced by their socioeconomic characteristics (Lee et al., 2015) ${ }^{(23)}$. Meanwhile, Tchente Nguefack et al. (2019) ${ }^{(24)}$, in a study in Cameroon found that women's higher level of education was protective against UTI in pregnancy.

The implementation of the present study educational intervention based on HBM led to significant improvements in the scores of knowledge, health behavior practices, and HBM among the women in the study group. The independent effect of the intervention was confirmed in multivariate analyses models for these three variables. This success of the intervention could be attributed to its content that filled knowledge gaps and corrected misconceptions in HBM framework that motivated attendants. Moreover, the use of adult learning approaches in the implementation of the program encouraged the process of learning among them. In agreement with these results, an intervention study in Philippines reported significant improvements in pregnant women's knowledge and hygienic practices following an educational intervention (Navarro et al., 2019b) ${ }^{(25)}$.
In the current study, the severity and bothersome of UTI symptoms tended to be mild to moderate as indicated by their related scores. This might be explained by their high tolerance and habituation for such symptoms as frequency, heaviness, incomplete voiding, etc. They might attribute these symptoms to their pregnancy, particularly given that they were mostly multigravidas. Moreover, more than a half of the women in the current study sample reported a positive history of previous UTI, which might influence their symptoms. In line with this, a history of previous UTI increased pregnant women's risk of UTI more than eightfold as shown by Belete (2020) ${ }^{(26)}$, in a study in Ethiopia.

The implementation of the study intervention was associated with significant improvements in symptoms severity and bothersome. However, this was through improving women's knowledge based on their HBM as depicted in the multivariate analysis. Meanwhile, time was also an independent predictor of symptom improvement. Hence, women in both groups had significant decreases in their scores of symptoms severity and bothersome, which is attributed to the treatment course followed; however, the degree of improvement was twofold among the 
women in the study group in comparison with those in the control group. This confirms the positive impact of the intervention on UTI symptoms. The improvement in women's practices would also certainly have a positive impact of their UTI prognosis, especially those related to personal hygiene as has been reported in a systematic review by Ghouri et al. (2018) ${ }^{(27)}$.

Apart from the subjective women's feeling of improved UTI symptoms' severity and bothersome, the present study has also used objective indicators of improvement, namely urine analysis and culture. This was essential since some of the urinary symptoms associated with pregnancy may resemble UTI symptoms as highlighted by Sekikubo et al. (2017) ${ }^{(28)}$, in a study in Uganda and thus culture is essential for follow-up of treatment (Rosana et al., 2020) ${ }^{(29)}$.

The findings of the present study revealed significantly less pus cells in urine and positive cultures among the women in the study groups compared to those in the control group. This was noticed both at the end of the treatment course as well as at the 3-month follow-up examination. Such improvement is certainly attributed to the study intervention as shown in the logistic regression analysis model, and this was due to the use of the HBM framework in the application of the intervention as this model has also demonstrated. The high HBM scores of the study group women might also explain their significantly better compliance, and this could have contributed to their better UTI prognoses and outcomes. Similar successes of the application of the HBM in interventions aimed at improving pregnant women's knowledge and practices related to physical activity (Shafieian and Kazemi, 2017) ${ }^{(30)}$, nutrition modification (Araban et al., 2017) ${ }^{(31)}$, and gestational diabetes (Mohebbi et al., 2019) ${ }^{(32)}$, were reported, but no study could be identified in relation to UTI in pregnancy.

Nonetheless, still a relatively large percentage of the women in the study and control groups of the present study were having pus cells at the post and follow-up examination, but with negative culture and no symptoms, which is in agreement with the findings of (Hooton et al 2020) ${ }^{(33)}$, in a study of asymptomatic bacteriuria and pyuria in women in the United States.

\section{Conclusion and Recommendations}

The use of a Health Belief Model (HBM) framework in the implementation of an educational program for UTI in pregnancy is effective in the relief of symptoms and in cure. The program and its booklet should be implemented in ANC settings. Given the limitations of the quasi- 
intervention design, it is recommended to replicate this study in a randomized clinical trial design for stronger evidence.

\section{References}

1. Ahmadi Z., Shamsi M., Roozbahani N., and Moradzadeh R. The effect of educational intervention program on promoting preventive behaviors of urinary tract infection in girls: a randomized controlled trial. BMC Pediatr. 2020; 20(1):79. Published 2020 Feb 19. doi:10.1186/s12887-020$\underline{1981-\mathrm{x}}$

2. Yazdi S., Alidousti K., Tirgari B., and Jahani Y. Effect of integrated health promotion intervention and follow up on health issues (clothing way, food habits, urinary habits, sexual behavior habits) related to urinary tract infection among pregnant women. A randomized, clinical trial. J Prev Med Hyg. 2020;61(2): E194-E199. Published $2020 \quad$ Jul 4. doi:10.15167/2421-

3. Navarro A., Sison J.M., and Puno R. Reducing the incidence of pregnancyrelated urinary tract infection by improving the knowledge and preventive practices of pregnant women. Eur J Obstet Gynecol Reprod Biol.2019a;241:88-93.

doi:10.1016/j.ejogrb.2019.08.018.
4. Sujatha R., and Nawani M. Prevalence of asymptomatic bacteriuria and its antibacterial susceptibility pattern among pregnant women attending the antenatal clinic at kanpur, India. J Clin Diagn Res. 2014;8:DC01-DC3. https://doi.org/10.7860/JCDR/2014/65 99.420510.7860/JCDR/2014/6599.420

5. Azami M., Jaafari Z., and Masoumi M. The etiology and prevalence of urinary tract infection and asymptomatic bacteriuria in pregnant women in Iran: a systematic review and Meta-analysis. BMC Urol. 2019;19(1):43. Published 2019 May 30. doi:10.1186/s12894-019-0454-8

6. Clouse K., Shehabi A., and Suleimat A.M. High prevalence of Group B Streptococcus colonization among pregnant women in Amman, Jordan. BMC Pregnancy Childbirth. 2019;19(1):177. Published 2019 May 20. doi:10.1186/s12884-019-2317-4.

7. Darabi F., Kaveh M.H., Khalajabadi Farahani F., Yaseri M., Majlessi F., and Shojaeizadeh D. The effect of a theory of planned behavior-based educational intervention on sexual and reproductive health in Iranian adolescent girls: a randomized controlled trial. J Res Health Sci. 2017;17(4): e00400. 
8. Nahidi F., Dolatian M., Roozbeh N., Asadi Z., and Shakeri N. Effect of health-belief-model-based training on performance of women in breast selfexamination. Electron Physician. 2017;9(6):4577-4583. Published 2017 Jun 25. doi:10.19082/4577.

9. Parsa P., Sharifi F., Shobeiri F., and Karami M. Effects of group counseling based on health belief model on cervical cancer screening beliefs and performance of rural women in Kaboudrahang, Iran. Asian Pac J Cancer Prev. 2017;18(6):15251530. Published 2017 Jun 25. doi:10.22034/APJCP.2017.18.6.1525

10. Munene A., Lockyer J., Checkley S., and Hall D.C. (): Exploring Well Water Testing Behaviour Through the Health Belief Model. Environ Health Insights. 2020;14:1178630220910143. Published $2020 \quad$ Mar 11. doi:10.1177/1178630220910143.

11. Khoramabadi M., Dolatian M., and Hajian S. Effects of education based on health belief model on dietary behaviors of Iranian pregnant women. Glob J Health Sci. 2015;8(2):230-239. Published 2015 Jun 25. doi:10.5539/gjhs.v8n2p230
12. Jeihooni A.K., Jamshidi H., Kashfi S.M., Avand A., and Khiyali Z. (): The effect of health education program based on health belief model on oral health behaviors in pregnant women of Fasa City, Fars Province, South of Iran. J Int Soc Prev Community Dent. 2017;7(6):336-343.

\section{doi:10.4103/jispcd.JISPCD 339_17.}

13. Lee A.C., Mullany L.C., and Quaiyum M. Effect of population-based antenatal screening and treatment of genitourinary tract infections on birth outcomes in Sylhet, Bangladesh (MIST): a cluster-randomized clinical trial. Lancet Glob Health. 2019;7(1):e148-e159.

doi:10.1016/S2214-109X(18)30441-8.

14. Chow S-C, Shao J, Wang H. Sample size calculations in clinical research. 2nd ed. 2008.Boca Raton: Chapman \& Hall/CRC; Section 3.2.1, page 58.

15. Hulley SB, Cummings SR, Browner WS, Grady D, Newman TB. (): Designing clinical research: an epidemiologic approach. 4th ed. 2013. Philadelphia, PA: Lippincott Williams \& Wilkins; Appendix 6A, page 73.

16. Clayson D., Wild D., Doll H., Keating K., Gondek K.Validation of a patient-administered questionnaire to 
measure the severity and bothersomeness of lower urinary tract symptoms in uncomplicated urinary tract infection (UTI): the UTI Symptom Assessment questionnaire. 2005;96(3):350-359.

Published2005,July24doi:10.1111/j.14 $\underline{64-410 X .2005 .05630}$

17. Higgins C. Urine microscopy, culture and sensitivity, understanding laboratory investigations a guide for nurses, midwives and healthcare professionals. $3^{\text {rd }}$ ed., 2013.Oxford: johen wiley and sons ltd Uk;325-337.

18. Pernille H., Lars B., Marjukka M., Volkert S., and Anne H. Sampling of urine for diagnosing urinary tract infection in general practice - Firstvoid or mid-stream urine. Scand $\mathbf{J}$ Prim Health Care. 2019;37(1):113119.:10.1080/02813432.2019.156870.

19. Noya C., Alkon A., Castillo E., Kuo A.C., and Gatewood E. Shared medical appointments: an academiccommunity partnership to improve care among adults with type 2 diabetes in California Central Valley Region. Diabetes Educ. 2020;46(2):197-205. doi:10.1177/01 45721720906792.
20. Gessese Y.A., Damessa D.L., and Amare M.M. Urinary pathogenic bacterial profile, antibiogram of isolates and associated risk factors among pregnant women in Ambo town, Central Ethiopia: a crosssectional study. Antimicrob Resist Infect Control. 2017; 6:132. Published 2017 Dec 29. doi:10.1186/s13756017-0289-6.

21. Kant S., Lohiya A., Kapil A., and Gupta S.K. Urinary tract infection among pregnant women at a secondary level hospital in Northern India. Indian J Public Health. 2017;61(2):118-123. doi:10.4103/ijph. IJPH_293_15.

22. Donkor E.S., Horlortu P.Z., Dayie N.T., Obeng-Nkrumah N., and Labi A.K. Community acquired urinary tract infections among adults in Accra, Ghana. Infect Drug Resist. 2019; 12:2059-2067. Published 2019 Jul 11. doi:10.2147/IDR.S204880.

23. Lee A.C., Quaiyum M.A., and Mullany L.C. (): Screening and treatment of maternal genitourinary tract infections in early pregnancy to prevent preterm birth in rural Sylhet, Bangladesh: a cluster randomized trial. Tchente Nguefack C., Okalla Ebongue C., Nouwe Chokotheu C., Ebong Ewougo C., Nana Njamen T., and 
Mboudou E. Clinical presentation, risk factors and pathogens involved in bacteriuria of pregnant women attending antenatal clinic of 3 hospitals in a developing country: a cross sectional analytic study. BMC Pregnancy Childbirth. 2019;19(1):143. Published 2019 Apr 29. doi:10.1186/s12884-019-2290-y.

24. Navarro A., Tiongco R.E., and Bundalian R.: Knowledge, attitude, practices, and health beliefs of pregnant women about urinary tract infection and its associated risk factors: a local Filipino community experience. Kesmas: National Public Health Journal. 2019b;14 (2): 82-87. (doi: 10.21109/kesmas.v14i2.3111) .

25. Belete M.A. Bacterial profile and ESBL screening of urinary tract infection among asymptomatic and symptomatic pregnant women attending antenatal care of northeastern Ethiopia region. Infect Drug Resist. 2020; 13:2579-2592BMC Pregnancy Childbirth. 2015;15:326. Published $2015 \quad$ Dec 7. doi:10.1186/s12884-015-0724-8.

26. Belete M.A. Bacterial profile and ESBL screening of urinary tract infection among asymptomatic and symptomatic pregnant women attending antenatal care of northeastern Ethiopia region. Infect Drug Resist. 2020; 13:2579-2592. Published 2020 Jul 28. doi:10.2147/IDR.S258379

27. Ghouri F., Hollywood A., and Ryan K. A systematic review of non-antibiotic measures for the prevention of urinary tract infections in pregnancy. BMC Pregnancy Childbirth. 2018;18(1):99. Published 2018 Apr 13. doi:10.1186/s12884-018-1732-2.

28. Sekikubo M., Hedman K., Mirembe F., and Brauner A. Antibiotic overconsumption in pregnant women with urinary tract symptoms in Uganda. Clin Infect Dis. 2017;65(4):544-550.

doi:10.1093/cid/cix356.

29. Rosana Y., Ocviyanti D., and Halim M. Urinary tract infections among Indonesian pregnant women and its susceptibility pattern. Infect Dis Obstet Gynecol.; 2020:9681632. Published 2020 Apr 21. doi:10.1155/2020/9681632.

30. Shafieian M., and Kazemi A. A randomized trial to promote physical activity during pregnancy based on health belief model. J Educ Health 
Promot. 2017.;6:40. Published 2017

May 5. doi:10.4103/jehp.jehp_19_15.

31. Araban M., Baharzadeh K., and Karimy M. Nutrition modification aimed at enhancing dietary iron and folic acid intake: an application of health belief model in practice [published correction appears in Eur $\mathbf{J}$ Public Health.;27(3):582]. Eur J Public Health. 2017;27(2):287-292.

doi:10.1093/eurpub/ckw238

32. Mohebbi B., Tol A., Sadeghi R., Mohtarami S.F., and Shamshiri A. Self-management Intervention Program Based on the Health Belief Model (HBM) among Women with Gestational Diabetes Mellitus: A Quazi-Experimental Study. Arch Iran Med.2019;22(4):168-173.

33. Hooton T.M., Roberts P.L., and Stapleton A.E. Asymptomatic Bacteriuria and Pyuria in Premenopausal Women [published online ahead of print, 2020 Mar 16]. Clin Infect Dis. 2020; ciaa274. doi:10.1093/cid/ciaa274 